\title{
Analysis of Tensile and Shear Strength Research Results of a Deformable Adhesive in a Lightweight Floor System
}

\author{
Jacek Karpiesiuk* \\ Department of Building Expert in construction and building, Bialystok University of Technology, Poland \\ *Corresponding author: Jacek Karpiesiuk, Department of Building Expert in construction and building, Bialystok University of \\ Technology, Poland
}

\begin{abstract}
The article statistically analyzes experimental tests on a light floor system (LFS) without screeds. The results of over two years of experiments in which the strength of C2S1 and C2S2 cement deformable adhesive for tensile and shearing were tested allow to determine the confidence interval for the expected value of these strengths along with determining the relative precision of the estimation. In the article, only the C2S1 adhesive was analyzed because it meets two important criteria. It has relatively high mechanical strength and is more economically advantageous (purchase price 2-3 times lower than C2S2). The obtained data also allowed to verify the hypothesis regarding the minimum strength of the C2S1 adhesive during the pull-off test and shear strength.
\end{abstract}

Keywords: Deformable adhesive C2S; Statistical analysis; Lightweight floor system; Experimental research

\section{Introduction}

Tests of tensile and shear strength of mortars adhesive, after the preparation of samples, took place from July 2016 to October 2018. Tensile strength tests of adhesives perpendicular to the frontal surfaces (tensile strength) were carried out in dry conditions and water absorption in accordance with the standard [1]. The shear strength of adhesives was made by using PressoMess according to the manufacturer's instructions. These tests were described in [2-4], and concerned a lightweight floor system, where the underlaying material was EPS 200 hydro or XPS 300 thermal insulation with a rough or waffle surface. The floor made from tiles was directly attached to the insulating underlay using deformable mortars adhesive of the $\mathrm{C} 2 \mathrm{~S} 1$ or C2S2 class, reinforced with a glass fiber mesh of various weights from $145-320 \mathrm{~g} / \mathrm{m}^{2}$. The test results indicate their insignificant dependence on the weight of the mesh embedded in the adhesive, as described in [4]. An exemplary vertical section of a light floor system is shown in Figure 1, and photographs of test stands in (Figures 2-4). The results of all tests are given in tables 1 and 2. In the conclusions of the article [4], it was found that after the tests of tensile and shear strength optimal construction of a lightweight floor in terms of economic and strength, meeting even the criteria for stronger dispersion adhesives acc. [5] is composed of:

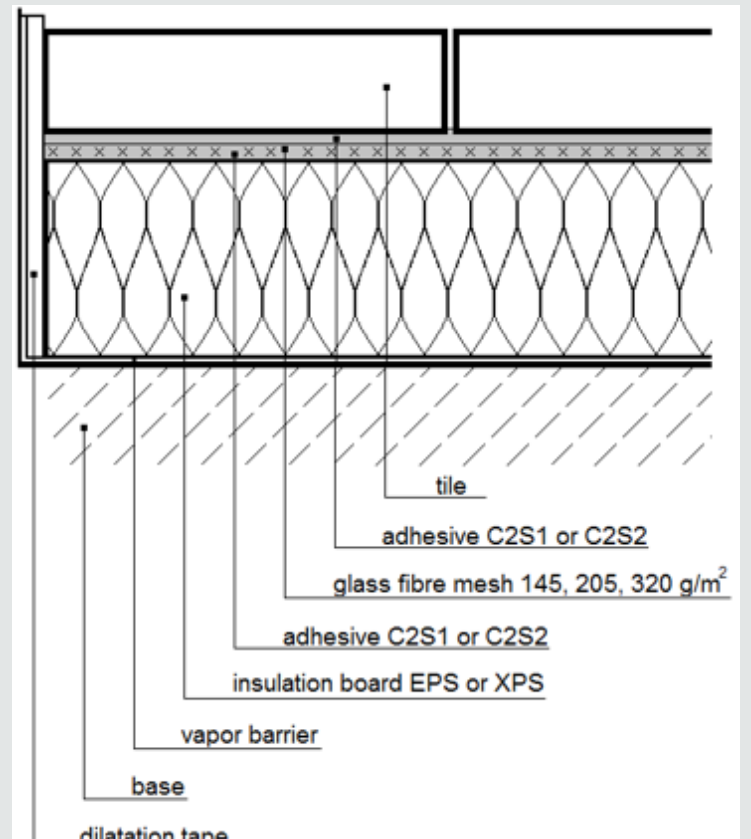

Figure 1: Cross-section of a lightweight floor system with XPS or EPS thermal insulation. 


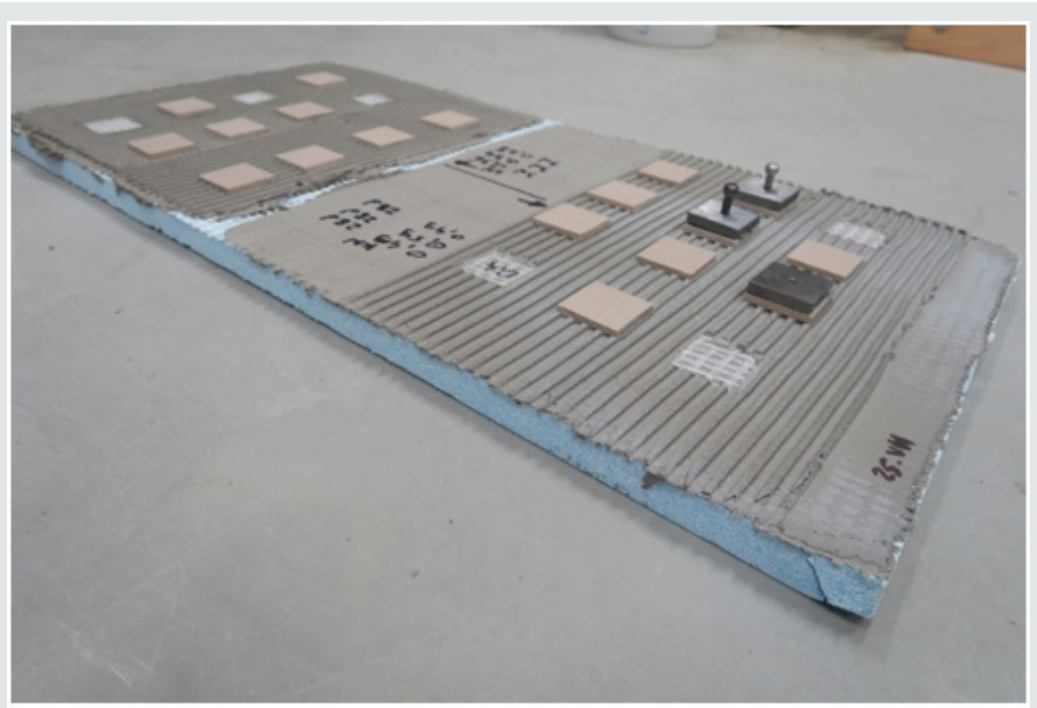

Figure 2: An example of a research stand, for adhesion measurements, using the pull-off method.

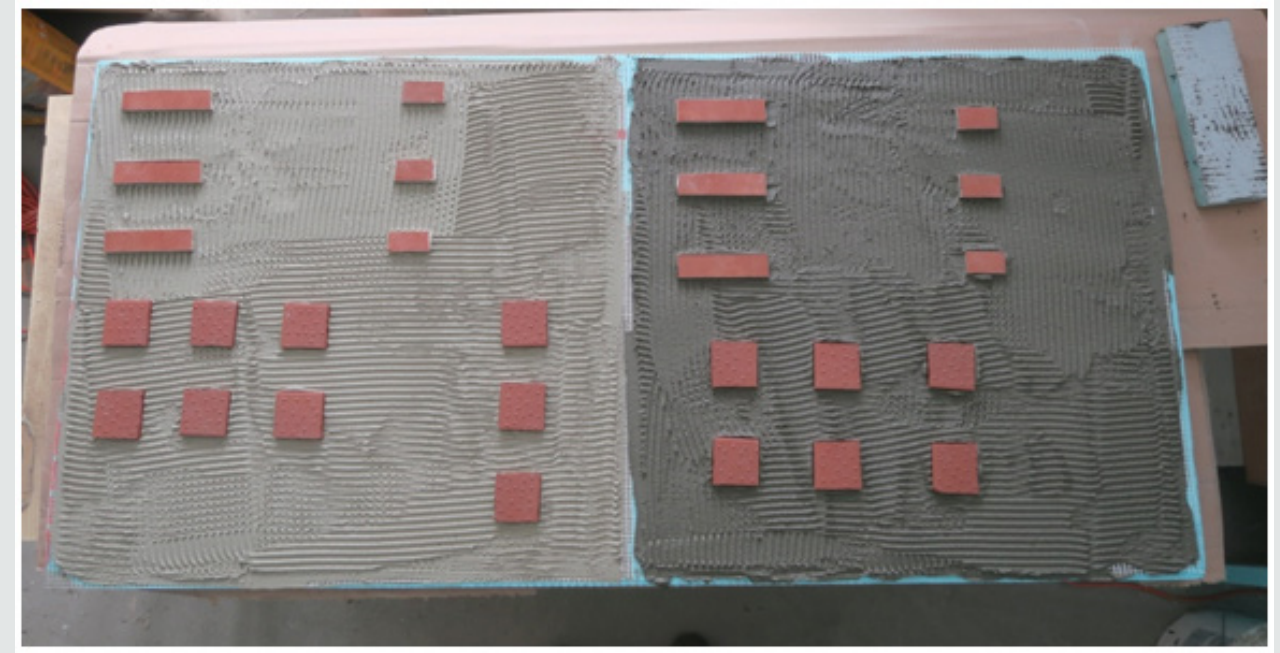

Figure 3: An example of a research stand, for adhesion measurements of C2S1 and C2S2, using the pull-off method and shear strength tests.

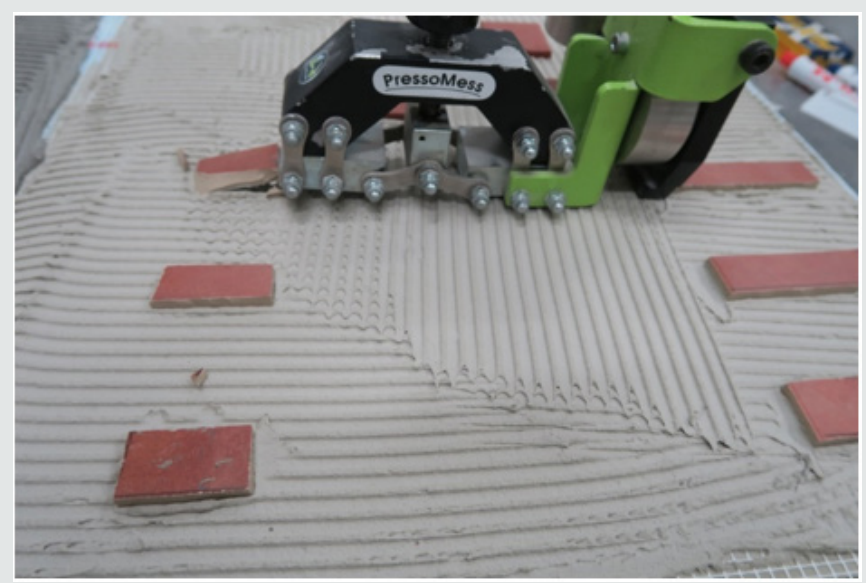

Figure 4: PressoMess for shear strength testing. 
Table 1: The results of pull-off and shear strength tests of the C2S1 adhesive in the entire population with EPS and XPS insulating substrate with various humidity conditions.

\begin{tabular}{|c|c|c|c|c|c|c|}
\hline \multirow{3}{*}{$\mathrm{Nr}$} & \multicolumn{6}{|c|}{ C2S1 adhesive } \\
\hline & \multicolumn{3}{|c|}{ EPS insulation } & \multicolumn{3}{|c|}{ XPS insulation } \\
\hline & Pull-off (dry) [MPa] & Pull-off (wet) [MPa] & Shear [MPa] & Pull-off (dry) [MPa] & Pull-off (wet) [MPa] & Shear [MPa] \\
\hline 1 & 0.196 & 0.2 & 0.4 & 0.308 & 0.176 & 0.5 \\
\hline 2 & 0.236 & 0.184 & 0.4 & 0.248 & 0.168 & 0.6 \\
\hline 3 & 0.196 & 0.168 & 0.6 & 0.288 & 0.196 & 1.1 \\
\hline 4 & 0.176 & 0.164 & 0.65 & 0.308 & 0.236 & 1 \\
\hline 5 & 0.1 & 0.212 & 0.5 & 0.32 & 0.26 & 1 \\
\hline 6 & 0.164 & 0.188 & 0.5 & 0.34 & 0.212 & 1.15 \\
\hline 7 & 0.112 & 0.248 & 0.55 & 0.136 & 0.184 & 1 \\
\hline 8 & 0.184 & 0.144 & 0.55 & 0.164 & 0.3 & 0.9 \\
\hline 9 & 0.184 & 0.308 & 0.65 & 0.228 & 0.212 & 1.2 \\
\hline 10 & 0.228 & 0.216 & 0.65 & 0.236 & 0.272 & 1.4 \\
\hline 11 & 0.208 & 0.244 & 0.45 & 0.3 & 0.228 & 1.2 \\
\hline 12 & 0.236 & 0.2 & & 0.248 & 0.248 & \\
\hline 13 & 0.236 & & & 0.208 & & \\
\hline 14 & 0.26 & & & 0.268 & & \\
\hline 15 & 0.3 & & & 0.248 & & \\
\hline 16 & 0.236 & & & 0.268 & & \\
\hline 17 & & & & 0.248 & & \\
\hline
\end{tabular}

Table 2: The results of pull-off and shear strength tests of the C2S2 adhesive in the entire population with EPS and XPS insulating substrate with various humidity conditions.

\begin{tabular}{|c|c|c|c|c|c|c|}
\hline \multirow{3}{*}{$\mathrm{Nr}$} & \multicolumn{6}{|c|}{ C2S2 adhesive } \\
\hline & \multicolumn{3}{|c|}{ EPS insulation } & \multicolumn{3}{|c|}{ XPS insulation } \\
\hline & Pull-off (dry) [MPa] & Pull-off (wet) [MPa] & Shear [MPa] & Pull-off (dry) [MPa] & Pull-off (wet) [MPa] & Shear [MPa] \\
\hline 1 & 0.2 & 0.36 & 1.6 & 0.32 & 0.352 & 2.1 \\
\hline 2 & 0.196 & 0.352 & 1.4 & 0.248 & 0.332 & 1.9 \\
\hline 3 & 0.312 & 0.3 & 1.15 & 0.32 & 0.32 & 1.9 \\
\hline 4 & 0.3 & 0.292 & 1.5 & 0.308 & 0.188 & 1.2 \\
\hline 5 & 0.3 & 0.248 & 1.1 & 0.248 & 0.264 & 0.8 \\
\hline 6 & 0.268 & 0.26 & 1.2 & 0.28 & 0.28 & 0.8 \\
\hline 7 & 0.236 & 0.212 & 1.25 & 0.28 & 0.368 & 1.5 \\
\hline 8 & 0.324 & 0.268 & 1.1 & 0.26 & 0.368 & 1.3 \\
\hline 9 & 0.288 & 0.248 & 1 & 0.268 & 0.36 & 1.6 \\
\hline 10 & 0.308 & & & & & \\
\hline 11 & 0.268 & & & & & \\
\hline 12 & 0.3 & & & & & \\
\hline 13 & 0.288 & & & & & \\
\hline
\end{tabular}
a) XPS rough thermal insulation
b) Cement adhesive type C2S1
c) Tiles

For this reason, the article deals with the analysis of the light floor system (LFS) with the adhesive layer of the C2S1 class on various substrates to:
I. Determine the confidence interval for the value of the expected tensile and shear strength of the C2S1 adhesive together with the determination of the relative precision of the estimation.

II. Verify the hypothesis regarding the minimum strength of the C2S1 adhesive for the pull-off method and shear strength tests. 


\section{Results of Calculation}

Determination of the confidence interval for the value of the expected tensile and shear strength of the C2S1 adhesive together with the determination of the relative precision of the estimation, according to [6]. Table 3 lists the test results from the sample, after rejecting the selected extreme stress values given in Table 1 , considered as errors in sample preparation. Based on these data, the necessary calculations were made according to designs (1), (2) and they were placed at the bottom of Table 3. The calculation assumes a $90 \%$ confidence level due to the fact that assuming a $95 \%$ confidence level, the relative precision of estimation in some of the test samples was greater than $10 \%$. The calculation was based on the formula for the range of interval estimation of the expected tensile and shear strength value for the C2S1 adhesive mortar (1) and the formula for the relative precision of estimation $\delta(2)$.

Table 3: The results of pull-off and shear strength tests for the C2S1 adhesive from the sample together with the relative $\delta$ data and the absolute precision estimation $\Delta$.

\begin{tabular}{|c|c|c|c|c|c|c|}
\hline \multirow{3}{*}{$\mathbf{N r}$} & \multicolumn{6}{|c|}{ C2S1 adhesive } \\
\hline & \multicolumn{3}{|c|}{ EPS insulation } & \multicolumn{3}{|c|}{ XPS insulation } \\
\hline & Pull-off (dry) [MPa] & Pull-off (wet) [MPa] & Shear [MPa] & Pull-off (dry) [MPa] & Pull-off (wet) [MPa] & $\begin{array}{l}\text { Shear } \\
\text { [MPa] }\end{array}$ \\
\hline [MPa] & 0.2 & 0.36 & 1.6 & 0.32 & 0.352 & 2.1 \\
\hline 1 & 0.196 & 0.2 & 0.6 & 0.308 & 0.176 & 1.1 \\
\hline 2 & 0.236 & 0.184 & 0.65 & 0.248 & 0.196 & 1 \\
\hline 3 & 0.196 & 0.168 & 0.5 & 0.288 & 0.236 & 1 \\
\hline 4 & 0.176 & 0.164 & 0.5 & 0.308 & 0.26 & 1.15 \\
\hline 5 & 0.164 & 0.212 & 0.55 & 0.32 & 0.212 & 1 \\
\hline 6 & 0.184 & 0.188 & 0.55 & 0.34 & 0.184 & 0.9 \\
\hline 7 & 0.184 & 0.248 & 0.65 & 0.228 & 0.212 & 1.2 \\
\hline 8 & 0.228 & 0.216 & 0.65 & 0.236 & 0.272 & 1.2 \\
\hline 9 & 0.208 & 0.244 & 0.45 & 0.3 & 0.228 & \\
\hline 10 & 0.236 & 0.2 & & 0.248 & 0.248 & \\
\hline 11 & 0.236 & & & 0.208 & & \\
\hline 12 & 0.26 & & & 0.268 & & \\
\hline 13 & 0.236 & & & 0.248 & & \\
\hline 14 & & & & 0.268 & & \\
\hline 15 & & & & 0.248 & & \\
\hline $\mathrm{x}(2)$ & 0,210769 & 0,2024 & 0,566667 & 0,270933 & 0,2224 & 106,875 \\
\hline Sx & 0,029637 & 0,028485 & 0,075 & 0,037991 & 0,03212199 & 0,109992 \\
\hline $\mathrm{t}_{\alpha, \mathrm{s}}$ & 1.782 & 1.833 & 1.86 & 1.761 & 1.833 & 1.895 \\
\hline$\Delta$ & 0,015246 & 0,017404 & 0,049321 & 0,017881 & 0,01962654 & 0,078781 \\
\hline$\delta$ & $7,233,457$ & $8,598,887$ & $8,703,653$ & $6,599,622$ & 8.82488116 & 737,131 \\
\hline
\end{tabular}

$$
\bar{X}-\Delta<m<\bar{X}+\Delta
$$

Where:

$$
\begin{gathered}
\Delta=t_{\alpha, s} \frac{S_{x}}{\sqrt{n-1}} \\
\delta=\frac{\Delta}{\bar{x}} \times 100
\end{gathered}
$$

where:

$\delta$ - relative precision of estimation

$m_{o}$ - assumed expected value

$\mathrm{m}$ - expected value

$\bar{X}$ - the arithmetic mean of the random sample
$\Delta-$ absolute precision of estimation

$\mathrm{t}_{\alpha, \mathrm{s}}$ - reading from Student's $\mathrm{t}$-charts (for $\alpha=0,1$ )

$\mathrm{S}_{\mathrm{x}}-$ standard deviation from the sample

$\mathrm{n}$ - random sample size

The relative precision of the estimation is relatively high in all cases, which means that the interval estimation of the value of the expected tensile and shear strength of the C2S1 deformable adhesive on the basis of this random sample is possible with great caution. On the basis of the obtained results, it is possible to estimate the expected value of C2S1 adhesive strength with EPS and XPS insulation due to the fact that the relative precision of the estimation does not exceed 10\%. The range of the Neyman's confidence interval of the expected C2S1 strength adhesive value with these tests and the EPS or XPS insulation substrate is: 
a. pull-off (dry) with EPS: $0.1955<\mathrm{m}<0.2260 \mathrm{MPa}$

b. pull-off (wet) with EPS: $01850<\mathrm{m}<0.2198 \mathrm{MPa}$

c. shear with EPS: $0.5174<\mathrm{m}<0.6160 \mathrm{MPa}$

d. pull-off (dry) with XPS: $0.2530<\mathrm{m}<0.2888 \mathrm{MPa}$

e. pull-off (wet) with XPS: $0.2028<\mathrm{m}<0.2420 \mathrm{MPa}$

f. shear with XPS: $0.9900<\mathrm{m}<1.1475 \mathrm{MPa}$

The designated intervals are one of those that can be treated with $90 \%$ certainty to cover the expected strength value for C2S1 in individual research models. Comparing the obtained results, it can be claimed that $\mathrm{C} 2 \mathrm{~S} 1$ characterizes by the greater shear and tensile strength is characterized C2S1 with the XPS insulation than the EPS insulation in dry conditions. It confirms the assumption contained in the article [4].

Verification of hypotheses regarding minimum C2S1 adhesive strength according to [7], using the pull-off method in dry conditions with EPS insulation.

Based on the obtained results, we can hypothesize that the expected value of the C2S1 strength adhesive with EPS isolation using the pull-off method (dry conditions) is higher than 0,1955 MPa.

$$
\mathrm{H}_{0}: \mathrm{m}=0.1955 \quad \mathrm{H}_{1}: \mathrm{m}>0.1955
$$

Using the t-test to verify the null hypothesis we get:

$$
t=\frac{0.210769-0.1955}{0.29637} \cdot \sqrt{12} \approx 1.782
$$

Comparing the obtained result with the critical value $\mathrm{t} 2 \alpha, \mathrm{s}=$ t0.2; $12=1.356$ read from the Student's t-charts [6] at the righthanded alternative hypothesis, we can conclude that the test result is higher than the critical value (located in the critical area), which authorizes the rejection of the null hypothesis in favor of the alternative hypothesis. This means that for $90 \%$ certainty, the expected strength value of the C2S1 adhesive in EPS isolation using the pull-off method (dry conditions) is higher than 0.1955 MPa. In order to estimate the minimum strength of the C2S1 adhesive with EPS isolation using the pull-off method (dry conditions), with the results obtained from the carried-out samples, for $\alpha=0.10$ we can make calculations using the formula for the t-test:

$$
t=\frac{0.210769-m_{0}}{0.29637} \cdot \sqrt{12} \approx 1.356
$$

Hence

$$
m_{0}=0.210769-\frac{1.356-0.0296370}{\sqrt{12}}=0.199168 \approx 0.20 \mathrm{MPa}
$$

The obtained result can be treated with $90 \%$ certainty as the minimum strength of the C2S1 adhesive with EPS insulation for pull-off method with dry conditions.
Using the above procedure, the data from Table 3 and the formulas were determined the minimum strength of the C2S1 adhesive in other performed tests. They are:

a) in the pull-off method (wet conditions) with EPS insulation

$$
m_{0}=0.2024-\frac{1.383-0.028485}{\sqrt{9}}=0.18927 \approx 0.19 \mathrm{MPa}
$$

The obtained result can be treated with $90 \%$ certainty as the minimum strength of the C2S1 adhesive with EPS insulation for pull-off method (wet conditions). Critical value $\mathrm{t} 2 \alpha, \mathrm{s}=\mathrm{t} 0.2$ ; $9=1.383$ read from the Student's t-charts at the right-handed alternative hypothesis.

b) in the shear strength with EPS insulation

$$
m_{0}=0.566667-\frac{1.397-0.075}{\sqrt{8}}=0.52962 \approx 0.53 M P a
$$

The obtained result can be treated with $90 \%$ certainty as the minimum strength of the C2S1 adhesive with EPS insulation for shear strength. Critical value krytyczna $\mathrm{t} 2 \alpha, \mathrm{s}=\mathrm{t} 0.2 ; 8=1.397$ read from the Student's t-charts at the right-handed alternative hypothesis.

c) in pull-off method (dry conditions) with XPS insulation

$$
m_{0}=0.270933-\frac{1,345-0.037991}{\sqrt{14}}=0.25728 \approx 0.26 \mathrm{MPa}
$$

The obtained result can be treated with $90 \%$ certainty as the minimum strength of the C2S1 adhesive with XPS insulation for pull-off method (dry conditions). Critical value $\mathrm{t} 2 \alpha, \mathrm{s}=\mathrm{t} 0.2$ ; $14=1.345$ read from the Student's t-charts at the right-handed alternative hypothesis.

d) in pull off method (wet conditions) with XPS insulation

$$
m_{0}=0.2224-\frac{1.383-0.03212199}{\sqrt{7}}=0.20759 \approx 0.21 \mathrm{MPa}
$$

The obtained result can be treated with $90 \%$ certainty as the minimum strength of the C2S1 adhesive with XPS insulation for pull-off method (wet conditions). Critical value $\mathrm{t} 2 \alpha, \mathrm{s}=\mathrm{t} 0.2$ ; $9=1.383$ read from the Student's t-charts at the right-handed alternative hypothesis.

e) in shear strength with XPS insulation

$$
m_{0}=1.06875-\frac{1.415-0.109992}{\sqrt{7}}=1.00992 \approx 1.00 \mathrm{MPa}
$$

The obtained result can be treated with $90 \%$ certainty as the minimum strength of the C2S1 adhesive with XPS insulation for shear strength. Critical value krytyczna $\mathrm{t} 2 \alpha, \mathrm{s}=\mathrm{t} 0,2 ; 7=1,415$ read from the Student's t-charts at the right-handed alternative hypothesis. 


\section{Conclusion}

The statistical analysis of the C2S1 type adhesive strength for pull-off method in dry and wet conditions and shear strength in dry conditions, which combines the tiles of two types of EPS 200 or XPS 300 insulation substrate, showed that:

a) A higher minimum shear and tensile strength was demonstrated using an XPS insulating substrate relative to EPS

b) Minimum strengths of the $\mathrm{C} 2 \mathrm{~S} 1$ adhesive, which can be treated with $90 \%$ certainty

1. depending on the insulating base:

a. $0.20 \mathrm{MPa}$ with EPS insulation for pull-off method in dry condition

b. $\quad 0.19 \mathrm{MPa}$ with EPS insulation for pull-off method in wet condition

c. $0.26 \mathrm{MPa}$ with XPS insulation for pull-off method in dry condition

d. 0.21MPa with XPS insulation for pull-off method in wet condition

e. $0.53 \mathrm{MPa}$ with EPS insulation for shear strength

f. 1.00MPa with XPS insulation for shear strength

\section{Acknowledgement}

The author of the article would like to thank Mrs. Elzbieta Golabeska from the Bialystok University of Technology for providing statistical literature. The research was carried out as part of my own work from Bialystok University of Technology No. W/WBIIŚ/15/2019, financed from the subsidy provided by the Ministry of Science and Higher Education.

\section{References}

1. (2017) Adhesives for ceramic tiles - Part 2: Test methods: PN-EN 120042: 03.

2. Karpiesiuk J, Chyzy T (2017) The results of selected strength tests of the adhesive layer of radiant heater with lightweight construction. Civil and Environmental Engineering 8(4): 165-171.

3. Karpiesiuk J, Chyzy T (2018) The interface strength tests of lightweight floor with heating coil. Building Materials 12: 68-70.

4. Karpiesiuk J, Chyży T Effects of testing the strength parameters of the adhesive layer in a light floor system. Open Engineering (to be published).

5. (2012) PN-EN 12004+A1:Adhesives for tiles-Requirements, evaluation of conformity, classification and designation.

6. Luszniewicz A, Słaby T (2008) Statystyka z pakietem komputerowym STATISTICA PL, wydanie trzecie, zmienione. Wydawnictwo CH Beck, Warszawa, Poland.

7. Gołabeska E (2006) Jednowymiarowe analizy porównawcze struktur w: Statystyka w zarządzaniu. pod red A Luszniewicza, wydanie drugie poprawione. Wydawnictwo WSFiZ Białystok, Poland.

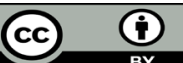

This work is licensed under Creative

To Submit Your Article Click Here:

Submit Article

DOI: $10.32474 /$ MAMS.2019.01.000122

Citation: Jacek Karpiesiuk. Analysis of Tensile and Shear Strength Research Results of a Deformable Adhesive in a Lightweight Floor System. 